\title{
Total diz artroplastisi ile ilişkili periprostetik kırıklar
}

\author{
Periprosthetic fractures associated with total knee arthroplasty
}

\author{
Nadir Özkayın, Can Yener
}

Ege Üniversitesi Tıp Fakültesi, Ortopedi ve Travmatoloji Bölümü, İzmir, Türkiye

Total diz artroplastisi sırasında veya sonrasında oluşan, diz çevresi periprostetik kırıkların insidansı gittikçe yükselmektedir. Bunun nedeni, yaşlı popülasyonun ve buna bağlı total diz artroplastisi yapılma sıklığının artması olarak açıklanabilir. Bu kırıkların ortaya çıkmasında rol oynayabilecek pek çok risk faktörü olduğu kabul edilmekle birlikte ana risk faktörü, özellikle yere düşme riski ve osteoporoz ile ilişkisi nedeniyle, ileri yaştır. Diz çevresi periprostetik kırıklarla ilgili sınıflamalar; kırığın deplasman miktarı, komponent gevşemesi olup olmaması, kırılma yeri, kalan distal kemik miktarı, kemik kalitesi ve redükte edilebilme gibi özelliklere odaklanmıştır. Nondeplase kırıklarda konservatif tedavi endike iken, deplase veya protez gevşemesi eşlik eden olgularda cerrahi önerilmektedir. Tedavi sonuçları dizilimi sağlama ve stabilite ile yakından ilişkilidir. Tedavinin ana hedefleri olan fonksiyonel iyileşme ve ağrısız eklem, total diz artroplastisi sonrası periprostetik kırığı olan hastaların çoğunda sağlanabilir. Bu derlemede, anlaşılması ve cerrahisi komplike olabilecek bu kırıkların genel özelliklerinden, geçerli sınıflama sistemlerinden ve güncel literatüre göre hangi kırık tipinde hangi cerrahi yöntemin önerildiğinden ve tedavi sonuçlarından bahsedilmiştir.

Anahtar sözcükler: total diz artroplastisi; periprostetik; kırık
The incidence of periprosthetic fractures around the knee which occurs during or after total knee arthroplasty is increasing. This may be explained by the increase in the elderly population and the frequency of total knee arthroplasty related to that. Although there are many risk factors that may play a role in the emergence of these fractures, the main risk factor is advanced age, especially because of the risk of falling to the ground and its relation to osteoporosis. Classifications related to periprosthetic fractures around the knee focus on features such as displacement of the fracture, component loosening, fracture site, remaining distal bone amount, bone quality and reduction. While conservative treatment is indicated in nondisplaced fractures, surgery is recommended in patients with displaced fractures or prosthetic loosening. Treatment results are closely related to providing alignment and stability. Functional restoration and painless joint, which are the main targets of treatment, can be provided in most patients with periprosthetic fractures after total knee arthroplasty. In this review, the general characteristics, the current classification systems, and the proposed surgical methods for certain types of these fractures and achieved results of the treatments which may be complicated and difficult to understand, are mentioned according to the current literature.

Key words: total knee arthroplasty; periprosthetic; fracture

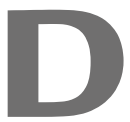

iz çevresi periprostetik kırıkları, total diz artroplastisi (TDA) sırasında veya sonrasında ortaya çıkan, diz eklemine $15 \mathrm{~cm}$ mesafe içinde veya varsa protezin intramedüller stemine $5 \mathrm{~cm}$ mesafe içinde oluşan kırıklardır. [1] TDA sonrası bu kırıkların oluşma insidansı femur için \%0,3-2,5 olarak belirtilirken $^{[2]}$, tibia için bu oran $\% 0,4-1,7^{[3]}$, patella için daha da az olarak bildirilmektedir. Bu kırıkların çok büyük bir çoğunluğu basit düşme gibi düşük enerjili travmalar sonucu oluşmaktadır. ${ }^{[4]}$ Bu kırıkların oluşma mekanizmasında rol oynayan faktörler arasında; femoral komponentin anterior kenarının stres kalkanı oluşturması, operasyon sonrası kan akımı azalmasıyla kemik remodelizasyonunun bozulması, içinde implant bulunan kemik kısım ile bulunmayan kemik kısım arasındaki elastik modulus farkı gösterilebilir. ${ }^{[5]}$ Bu kırıkların insidansının gittikçe yükselmesinin nedeni, yaşı ıopülasyonun ve buna bağlı TDA yapılma sıklığının artması olabilir.

- İletişim adresi: Dr. Can Yener, Ege Üniversitesi Hastanesi, Ortopedi Anabilim Dalı, İzmir, Türkiye

Tel: 0507 -3165334 e-posta: can.yener@yahoo.com

- Gelis tarihi: 19 Aralık $2018 \quad$ Kabul tarihi: 19 Aralık 2018 


\section{RISK FAKTÖRLERI}

TDA sonrası periprostetik kırıklar her hastada ortaya çıkabilmekle birlikte, hastaya bağlı ana risk faktörü özellikle yere düşme riski ve osteoporoz ile ilişkisi nedeniyle ileri yaştır. ${ }^{[6]}$ Bunun yanında, osteopeniye predizpozan olabilecek kortikosteroidlerin kronik kullanımı ve romatoid artrit $(R A)^{[7]}$ ile, buna ek olarak düşme riskini de arttırabilecek epilepsi, Parkinson hastalığı, serebellar ataksi, myastenia gravis, poliomiyelit, serebral palsi veya tanımlanmamış nöropatik eklemler gibi nörolojik anormallikler ve kardiyak patolojiler, diz çevresinde periprostetik kırıklar için hastaya bağlı risk faktörleri olarak sayılabilir. ${ }^{[7]}$ Periprostetik femur ve tibia kırıkları için bir diğer risk faktörü de kadın cinsiyet olarak tanımlanmıştır. ${ }^{[8]}$ Periprostetik patella kırıkları ise erkeklerde daha sık görülmüş ve bu, ekstansör mekanizma ile patella üzerine uygulanan mekanik güçlerin erkek hastalarda daha fazla olmasına bağlanmıştır. ${ }^{[8]}$ Diyabet hastalarının da, vasküler ve nörolojik komplikasyonlarına bağlı artmış düşme riski nedeniyle, periprostetik kırık riski altında olduğu düşünülmektedir.

Ameliyat sırasında diyafizer femoral kırıklar (genellikle anterior veya anterolateral kortikal penetrasyon ile) intramedüller (IM) kılavuzun yanlış yerleşimi nedeniyle ortaya çıkabilir. ${ }^{[9]}$ Özellikle osteopeni bulunan hastalarda, ameliyat sırasında metafizer kırıklar ortaya çıkabilir. Uygun olmayan kemik kesileri, bağ kesen posterior stabilize femoral komponentin agresif impaksiyonu ve deneme komponentlerinin eksentrik olarak yerleştirilmesi (özellikle revizyon cerrahisi sırasında) gibi teknik faktörler bu durumla sonuçlanabilir. ${ }^{[9]}$

Femoral periprostetik kırıklar için anterior femoral çentikleme, literatürde yaygın olarak tartışılmıştır. Kadavra çalışmaları ve biyomekanik çalışmalarda, anterior femoral çentiklemenin potansiyel olarak periprostetik kırık oluşumunda rol oynadığı belirtilmiştir. ${ }^{[10]}$ Gerekçe olarak, anterior femoral kortekste zayıflamayla fleksiyona ve rotasyonel kuvvetlere karşı direncin azalması gösterilmiştir. Fakat, klinik çalışmaların sonuçları halen tartışmalıdır. Ritter ve ark. ${ }^{[11]}$ ile Guiarathi ve ark.'nın ${ }^{[12]}$ yürüttüğü iki büyük geriye dönük olgu serisinde ise anterior femoral çentikleme ve distal femur periprostetik kırığı sıklığı arasında bir ilişki bulunamamıştır. Öte yandan Hoffmann ve ark. ${ }^{[13]}$, anterior femoral çentik ile periprostetik kırığın daha distal yerleşimli olması (anterior femoral çentik grubunda, kırığın femoral komponent anterior köşesine ortalama mesafesi 3,2 mm'ye karşın $39 \mathrm{~mm}$ ) ve implantın konulmasından kırık oluşmasına kadar geçen süre (anterior femoral çentik grubunda ortalama 37,5 aya karşın 80,3 ay) arasında istatistiksel olarak anlamlı bir ilişki olduğunu bildirmişlerdir.
Revizyon TDA varlığında, özellikle periprostetik femoral kırıklarda insidansın, olguların \%38'ine kadar yükselebildiği gösterilmiştir. ${ }^{[14]}$ Başka bir risk faktörü olarak, implant bileşenlerine bağlı periprostetik osteoliz, lokalize osteopeniye ve sonunda implant gevşetmesine neden olarak dizilim bozulmasına yol açabilir; bu da kırık riski oluşturabilir. ${ }^{[14]}$ Yine rotasyon yapma özelliği bulunmayan implantların, kemiğe artmış rotasyonel kuvvet aktarımı yaratarak periprostetik kırık riskini arttırdığı gösterilmiştir. ${ }^{[7]}$

Proksimal tibianın güçlü yapısı nedeniyle, ameliyat sırasında periprostetik tibia kırıkları daha nadirdir.[15] Ameliyat sırasında tibial periprostetik kırıklar, özellikle revizyon cerrahisi sırasında, iyi sabitlenmiş bir tibial komponentin kuvvetli retraksiyonu, eksentrik çimento kazınması, tibial komponentin agresif impaksiyonu ve tibial tüberkül osteotomisi gerçekleştirilmesi sırasında oluşabilir. ${ }^{[15]}$ Teorik olarak, posterior stabilize dizler ameliyat sırasında tibia kırı̆̆ına, bağ koruyan diz sistemlerine göre daha yatkındır. Bu kırıklar, genellikle posteriora yönlendirilen tibial komponent ve stemin impaksiyonu sonucu ortaya çıkar, vertikaldir ve çoğunlukla yer değiştirmez. ${ }^{[16]}$ Yine, tibial kanal hazırlanması sırasında eksentrik oyulursa kortikal penetrasyonla tibia kırı̆̆ı oluşturulabilir. ${ }^{[16]}$

Daha önceleri kullanılan total diz sistemlerinde periprostetik tibia kırıkları daha sık görülmesine rağmen, rotasyonel stabilite sağlayan "keeled" ve kısa tibial stemlerin kullanılmaya başlanmasıyla artık daha nadirdir. ${ }^{[17]}$ Periprostetik femoral kırıklar ile komponentlerin dizilim bozukluğu arasında açık bir ilişki saptanmamış ${ }^{[18]}$ iken, belirgin varus bozukluğunun tibial periprostetik kırıklarda potansiyel bir etiyolojik faktör olduğu düşünülmektedir. ${ }^{[17]}$ Yine, komponent gevşemesi durumunda tibial bir periprostetik kırık ortaya çıkması suprakondiler femoral kırıklara göre daha muhtemeldir. ${ }^{[17]}$

Patella kırıkları söz konusu olduğunda, patellar yüzey değişimi ile çok yakın ilişkilendirilmiştir. Bir literatür taramasında ${ }^{[8]}$, periprostetik patella kırıklarının \%99'unun yüzey değişimi yapılan patellalarda ortaya çıktığı ortaya konulmuştur. Aşırı ${ }^{[19]}$ veya yetersiz rezeksiyon $^{[20]}$, polimetilmetakrilat (PMMA) kullanımı ${ }^{[8]}$ ve osteonekroz yaratma ${ }^{[8]}$ gibi birçok teknik özelliğin, patellar yüzey değişimi sonrası oluşan kırıklarla ilişkili olduğu saptanmıştır. Osteonekroz gelişmesi, lateral gevşetme işlemi sırasında supero-lateral genikülat arter hasarı ile ilişkili bulunmuştur. Fakat bu konuda birbirinden çok farklı sonuçlar yayımlanmıştır. (\%51,2[8]'ye karşı \%0 ${ }^{[21]}$ olarak son derece farklıdır). Bu durum, cerrahi teknikle bağlantılı olarak daha agresif gevşetme uygulanan dizlerdeki arteriyel hasar ile ilişkili olabilir. 


\section{TANI}

Tanıda genellikle, travma öyküsü ve klinik muayene sonrasında standart iki yönlü diz grafileri yeterli olur. Patellar kırıktan şüphelenildiğinde tanjansiyel grafi istenmelidir. Bilgisayarlı tomografi (BT) şüpheli olgularda ve ameliyat öncesi planlamada yararlı olabilir.

\section{SINIFLAMALAR}

Rorabeck ve Taylor ${ }^{[22]}$, femoral periprostetik fraktürleri için, kırık yer değiştirmesi ve femoral komponentin tespit durumunu sorgulayan bir sınıflandırma önermiştir. Deplase olmayan kırıklar Tip I, 5 mm'den daha büyük deplasmanı olan veya $5^{\circ}$ 'den fazla bir açılanmaya sahip olan fakat komponent gevşemesi bulunmayan kırıklar Tip II ve deplasmandan bağımsız olarak komponent gevşemesi olan kırıklar Tip III kırık olarak isimlendirilmiştir (Tablo 1). Bu sınıflandırma yaygın olarak kullanılmasına rağmen, tedavi seçiminde de belirleyici olan kırılma yerini dikkate almamaktadır. Bu nedenle Su ve ark. ${ }^{[23]}$, kırığın femoral prostetik komponentten uzaklığına göre üç kırık tipi tanımlayan başka bir sınıflandırma sistemi geliştirmişlerdir (Tablo 1). Literatürde kullanılan diğer sınıflandırma sistemleri; kemik miktarı, kemik kalitesi ve redükte edilebilme gibi özelliklere odaklanmıştır. ${ }^{[24]}$ Bunlar, kırıkların tedavisi sırasında göz önünde bulundurulması gereken önemli faktörler olsa da, bu sistemlerin kırık deplasmanı ve özelliklerine değinmemesi kullanımlarını sınırlayabilir. Periprostetik femur kırıklarında sistematik bir tanı-tedavi algoritması oluşturulabilmesi için, kırığın deplasmanı ve yeri gibi temel özellikleri diğer destekleyici özelliklerle birleştirebilecek bir sınıflama sistemine ihtiyaç vardır. Tibial periprostetik kırıklarda yaygın olarak kullanılan, Felix ve ark. ${ }^{[15]}$ tarafından oluşturulmuş sınıflamada, 102 tibial periprostetik tibia kırığını incelemiş, anatomik konuma ve komponent tespitine göre sınıflandırmışlardır.

\section{TEDAVI SEÇENEKLERI VE SONUÇLARI}

\section{Femur}

\section{Ameliyat sırasında kırıklar}

Ameliyat sırasında periprostetik kırık insidansının, bu kırıkların bazıları farkedilmeyebileceği için olduğundan daha düşük olarak bildirildiği düşünülmektedir. [16] Bu kırıklardan femoral metafizyel olanlar genellikle vertikal oluşur ve sağlam bir periosteum ile deplase değildir. Bu kırıklar, ek bir müdahale olmaksızın yükten kurtarma ile tedavi edilebilir. ${ }^{[9]}$ Ameliyat sırasında femur şaftının kortikal bütünlüğünün penetre edilerek bozulduğu tespit edilirse, o zaman kemik grefti kullanılarak veya kullanılmadan yapılacak ve penetrasyon seviyesini femoral kanal çapının en az iki katı kadar mesafe geçecek stemli bir protez, tedavi için en iyi seçenektir. ${ }^{[16]}$ Komponent tespitini takiben kortikal penetrasyon görülürse veya ameliyat sonrası radyografilerde fark edilirse, 6-8 hafta boyunca yükten kurtarma, kortikal bozulma iyileşene kadar yeterli olabilir. ${ }^{[16]} \mathrm{Nadir}$ görülen deplase interkondiller veya tek kondil kırıkları, transkondiller vida tespiti ve femoral komponente intramedüller stem eklenmesi ile tedavi edilmelidir.[9,16]

\section{Ameliyat sonrası kırıklar}

Cerrahi dışı tedavi: Non-deplase kırıklarda konservatif tedavi endikedir, protez stabilse ve hastanın klinik durumu uygunsa, konsevatif tedavi sonuçları cerrahinin klinik sonuçları kadar iyi olabilir. ${ }^{[18]}$ Fakat, deplase periprostetik kırıklarda konservatif tedavi, sadece mobil olmayan hastalarda veya ağır komorbiditelerin varlığında endike olabilir. ${ }^{[2]} \mathrm{Bu}$ olgularda kapalı redüksiyon sonrası uzun bacak alçı atel veya menteşeli ortez ile immobilizasyon ve 4-6 hafta boyunca yükten kurtarma uygun endikasyon olabilir. ${ }^{[25]}$ Aynı şekilde, Moran ve ark.[26], non-deplase kırıkların konservatif tedavisinde iyi sonuçlar bildirmiş, fakat deplase kırıklı hastalarda klinik ve radyografik sonuçları cerrahi tedaviye göre daha kötü bulmuştur. Özetle, uzun süreli

Tablo 1. Femoral periprostetik fraktürleri için sınıflamalar

\begin{tabular}{lll}
\hline & Rorabeck ve Lewis sınıflaması & Su sınıflaması \\
\hline Tip I & Non-deplase kırık ve komponent stabil & Femoral komponentin proksimalindeki kırıklar \\
Tip II $\quad \begin{array}{l}\text { Deplase kırık ve } \\
\text { komponent stabil }\end{array}$ & $\begin{array}{l}\text { Femoral komponentin proksimal köşesinden başlayan ve } \\
\text { proksimale uzanan kırıklar }\end{array}$ \\
Tip III $\quad \begin{array}{l}\text { Komponent gevşemesi ve deplase veya } \\
\text { non-deplase kırıklar }{ }^{[2]}\end{array}$ & $\begin{array}{l}\text { Kırık hattı tamamıyla femoral komponentin proksimal köşesinin } \\
\text { distalinde olan kırıklar }\end{array}$
\end{tabular}


immobilizasyon, redüksiyonu koruma zorluğu, diz hareket açıklığ kaybı, dizilim bozukluğu ve kaynamama riski, deplase periprostetik kırıklarda konservatif tedavinin dezavantajlarıdır. ${ }^{[27]}$

Cerrahi tedavi: Kırı̆ı̆ı yeri, komponentin tespit durumu, hastanın kemik kalitesi ve kırık deplasman miktarı, tedavi stratejisini belirleyen en önemli faktörlerden bazılarıdır. ${ }^{[18]}$ Deplase ve redükte edilemeyen suprakondiller kırıklar, yeterli distal kemik stoğu varsa, hemen her zaman cerrahi gerektirir. ${ }^{[7,18]}$

Konvansiyonel plakların kullanımı, bu kırıkların tedavisi için neredeyse terkedilmiştir; implant yetmezliği ve komplikasyon oranları, kilitli kompresyon plakları ve intramedüller çiviler ile karşılaştırıldığında yüksektir. $^{[2,8,25]}$ Geleneksel konvansiyonel plaklar, varus çöküşüne yatkındır. ${ }^{[28]}$ Açılı kama plakları veya dinamik kondiller vida plakları gibi sabit açılı implantlar, çok distal kırıklar için veya derin intrakondiller kutuya sahip olan protezlerde sınılı bir uygulama alanına sahiptir; ancak yeterli distal parça bulunan kırıklarda başarılı bir şekilde kullanılabilir. ${ }^{[29]}$

Diz periprostetik kırıklarında birçok cerrah için tercih edilen tespit yöntemi olan kilitli kompresyon plaklarının avantajları; minimal invazivlik, osteoporotik kemikte tespit kuvveti ve prostetik implanta yakın bölgelerde metal serklaj yardımıyla monokortikal tespit yapabilme özelliğidir. ${ }^{[1,2,13]}$ Bu son özelliği, iki intramedüller implant arası kırıklarda daha da önem kazanmaktadır. ${ }^{[30]}$ Ayrıca, minimal invaziv olarak çok sayıda sabit açılı vida gönderebilme olanağı sağlayan bu plaklar, osteoporotik hastalarda tespit kuvvetini oldukça arttırmaktadır. ${ }^{[25]}$ Kilitli plak tespiti, radyografik iyileşme de göz önünde bulundurularak, erken aktif mobilizasyona ve ortalama 6-8 hafta sonra tam yüklenmeye izin verir. ${ }^{[2]}$

Periprostetik diz kırıklarının kilitli plak ile tespitinin klinik sonuçları, bildirilen gecikmiş kaynama ve kaynamama oranlarına rağmen genellikle tatmin edicidir. ${ }^{[2,8,26]}$ Henderson ve ark. ${ }^{[31]}$, kaynama oranının \%0-19 olduğu bildirilen bir meta-analiz yayımlamışlardır. Hoffmann ve ark. ${ }^{[13]}$ cerrahi invazivliği kaynamama için olası bir risk faktörü olarak belirtmişlerdir.

Esnek IM çiviler (Rush ve Ender çivileri), rotasyonel stabiliteyi sağlamadaki yetersizlikleri nedeniyle çoğunlukla terk edilmiştir. ${ }^{[32]}$ Rijid retrograd femoral çiviler, kilitleme vidasının yerleştirilmesine izin verecek kadar distal kırık parçası olan suprakondiller kırıklar için tercih edilen tespit yöntemidir. ${ }^{[33]} \mathrm{Bu}$ implantları kullanabilmek için protezin femoral komponenti, retrograd geçişe izin verecek şekilde 'open box' biçiminde tasarlanmış olmalıdır, posterioru stabilize bağ kesen komponentlerde kullanılamayabilir. ${ }^{[34]}$ Avantajları; minimal invaziv olması nedeniyle periostun tamamen korunması, düşük kan kaybı ve cerrahi süresinin çoğunlukla kısa olmasıdır. Klinik sonuçlar genellikle tatmin edicidir; birçok çalışmada, 12-16 haftada yaklaşık \%100'lük kaynama oranları bildirilmiştir. ${ }^{[35]}$ Retrograd çivileme, radyografik iyileşmeye de bakılarak erken aktif mobilizasyona ve ortalama 4-6 hafta sonra tam yüklenmeye olanak sağlar. ${ }^{[2]}$

Çivinin redüksiyon stabilitesi, kırığın distal parçasındaki kilitleme vidalarına bağlıdır, bu nedenle, en az iki bikortikal vida gereklidir ve protezin anterior-superior ucunun distaline yerleşmiş kırıklar, genellikle çiviyle zayıf bir stabilizasyon sağlar ve kaynamama riski daha yüksektir. ${ }^{[36]}$ Şiddetli osteoporoz durumunda, kilitli plaklar çivilemeye göre daha kararlı bir tespit sağlar. ${ }^{[14]}$ Son olarak; retrograd çivileme, iki implant arası stres oluşturarak yeni kırıklara yol açma potansiyeli bulunduğundan, proksimal IM implantlı veya kalça artroplastisi olan hastalarda kontrendikedir. ${ }^{[4]}$

Retrograd çivileme, özellikle valgus ve rekurvatumda, bir miktar yanlış kaynama ile ilişkilidir. Bunun nedeni, femoral komponent varlığında, giriş noktası ve kılavuz tel yönünün değişebilmesi olabilir. ${ }^{[37]}$ Bununla birlikte, Pelfort ve ark. ${ }^{[38]}$, bir miktar hiperekstansiyon bozukluğunun diz protezi stabilitesini veya fonksiyonel sonucu değiştirmediğini göstermiştir. Tersine, valgus deformitesi zor tolere edilir. Gliatis ve ark. ${ }^{[35]}$, retrograd çivilemeden sonra gelişen bir valgus deformitesinin protez revizyonuna gittiğini bildirmişlerdir.

Kilitli plaklama ve retrograd çivilemeyi karşılaştıran çalışmalar, ameliyat süresi, fonksiyonel iyileşme, tam yük verme zamanı, KSS (Knee Society Score) ve kaynama zamanı açısından anlamlı farklılık olmadığını bildirmektedir. ${ }^{[36]}$ Fakat, yanlış kaynama oranlarında kilitli plakların daha iyi olduğu istatiksel olarak anlamlı bildirilmiştir. ${ }^{\left[{ }^{[9]}\right]}$ Ayrıca son yıllarda bir kısım yazar, özellikle Su, Tip III gibi distal yerleşimli olan, osteoporotik hastalarda oluşan ve mediyal korteks desteği kaybolmuş kırıklarda çift taraflı kilitli plak kullanımını önermiştir (Şekil 1 ve 2). ${ }^{[40]}$

Protez gevşemesine veya malpozisyonuna neden olan kırıklarda protez revizyonu yapılmalıdır. Periprostetik kırıklarda internal tespitin kemik kalitesi veya kırık morfolojisi nedeniyle başarısız olduğu durumlarda da protez revizyonu önerilebilir (Şekil 3). ${ }^{[2,14]}$ Bu durumlarda, sağlam kemik kısmında stabil bir tespit elde etmek için yeterli uzunlukta stemli bir protez konulmalıdır. ${ }^{[2,14]}$ Birçok yazar iyi fonksiyonel iyileşme ve erken yük verebilme ile tatmin edici klinik sonuçlar bildirmiştir. ${ }^{[41]}$ İyi kemik stoğu olan hastalarda meydana gelen ve redükte edilebilir, yeterli distal kemik stoğu olan kırıklara protez gevşemesi eşlik ediyorsa, aynı operasyonda kırığın 

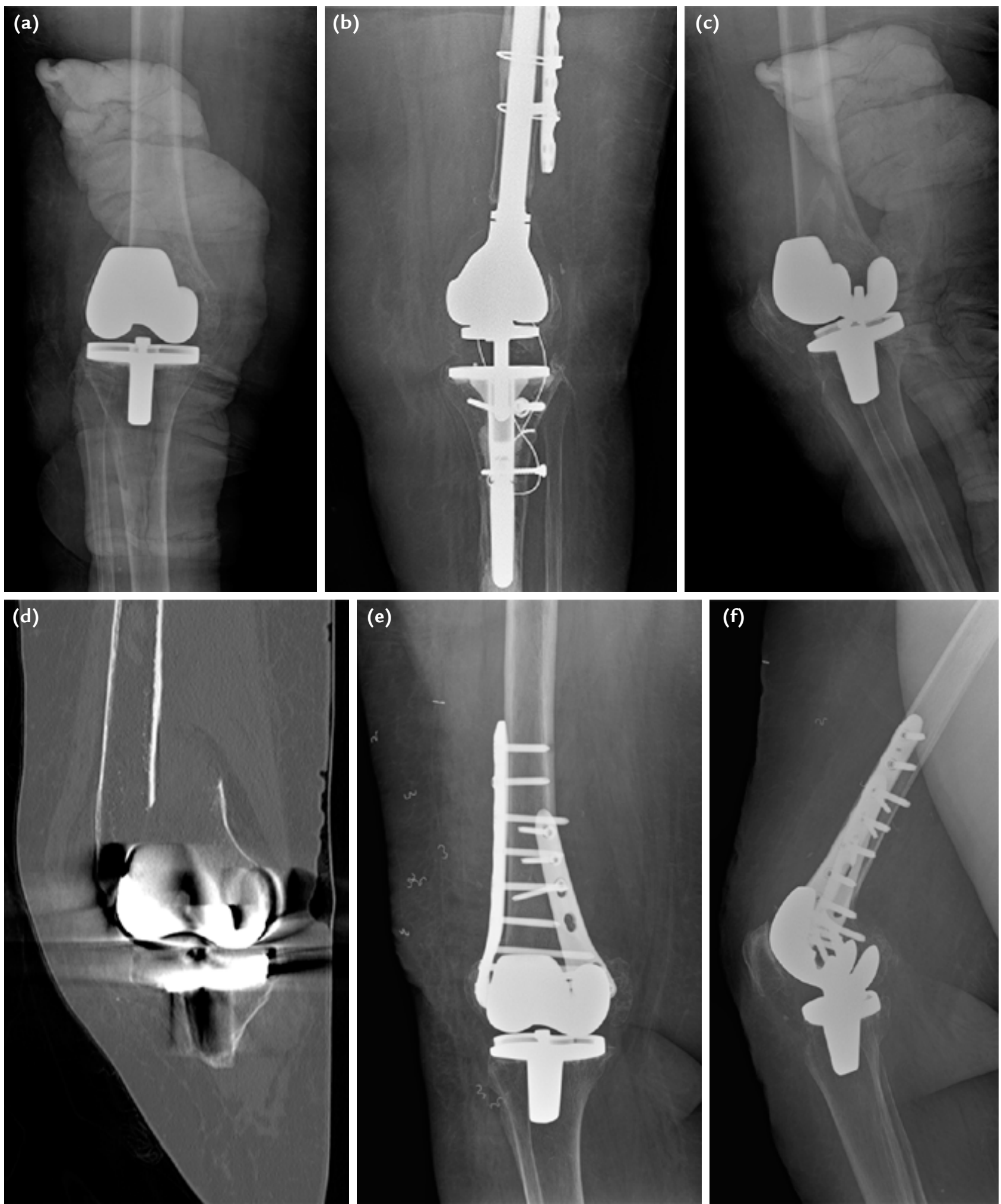

Şekil 1. a-f. Daha önce bilateral TDA yapılan ve sol diz internal tespit başarısızlığı sonrası distal femoral replasmana giden hastada, sağ dizde ortaya çıkan periprostetik kırık sonrası yapılan distal kilitli çift plak ile osteosentez: Sağ diz periprostetik kırık anterior-posterior (AP) grafi (a). Daha önce ameliyat edilen sol diz femoral replasmanın AP grafileri (b). Sağ diz periprostetik kırık lateral grafi (c). Sağ dizin kırık sonrası BT görüntüsü (d). Sağ periprostetik kırığın çift plak sonrası postop 12 . ay AP grafisi (e). Sağ dizin cerrahi sonrası 12. ay lateral grafisi (f). 


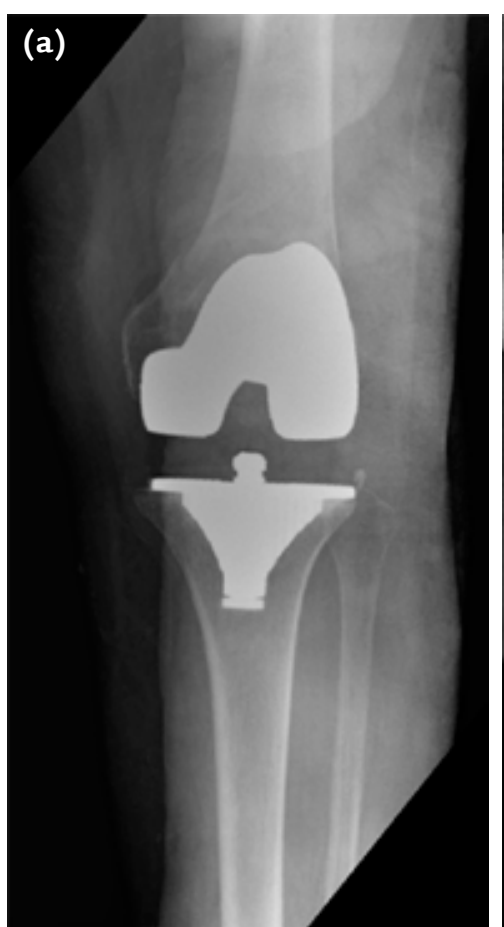

(d)

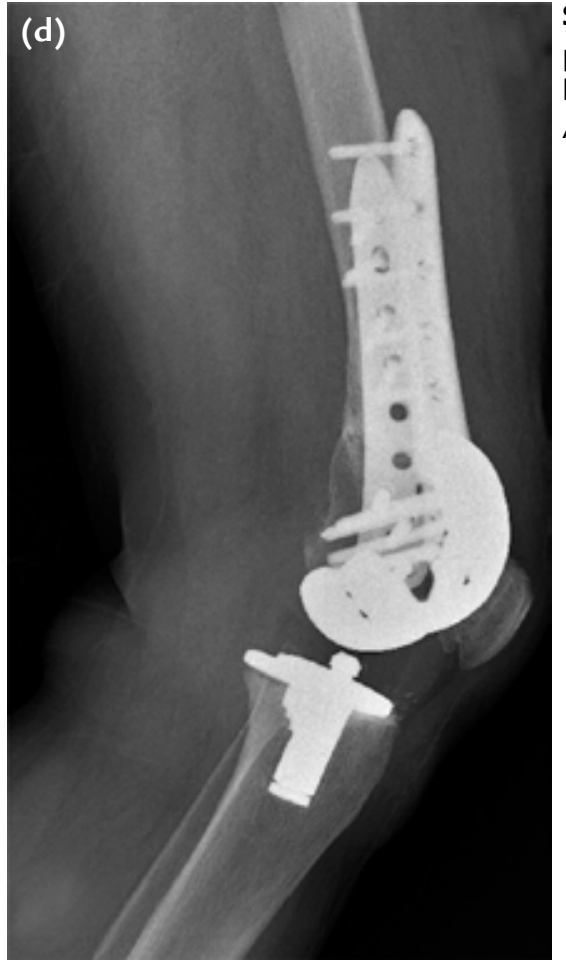

internal tespiti ile uzun stemli komponent kullanılarak revizyon artroplastisi yapılabilir. ${ }^{[24]}$ Periprostetik kırıklar sonrası diz protezi revizyonu, sıklıkla eklem hareket açıklığı (ROM) kaybı ile ilişkilidir. ${ }^{[41]}$ Bu komplikasyon, kemik ve yumuşak doku hasarının doğrudan bir sonucu olarak düşünülebilir. Yazarlar, ROM kaybını sınırlamak için cerrahi sonrası yeterli bir fizik tedavi programının önemini vurgulamışlardır. ${ }^{[41]}$

Osteopenik kemikte çok parçalı kırıklar, distal parçanın kemik kalitesi iyi değilse, genellikle ya yapısal allogreftli protez ${ }^{[42]}$ ya da distal femur replasmanıyla ${ }^{[43]}$ birlikte kırık parçanın eksizyonunu gerektirir. Distal femoral replasman, yaşlı ya da sedanter hastalar için en uygundur. ${ }^{[42]}$ Protezin gevşemesiyle ilgili potansiyel problem nedeniyle, genç hastalarda diğer tedavi seçeneklerinin göz önüne alınması gerekebilir. Tedavinin amacı kemik stoğunu korumaktır. Bu durumda, allogreft-prostetik kompozit (APC) kullanılabilir. ${ }^{[44]}$ APC kullanımı ile ilgili problemler arasında, enfeksiyonun daha sık görülmesi ve greft rezorpsiyonu yer almaktadır. ${ }^{[42]}$

Masif osteolizli, ciddi osteoporozlu, internal tespitin başarısız olduğu ve eklem instabilitesi eşlik eden hastalarda protez revizyonu zorlayıcı olabilir. Bu durumlarda, yapısal allogreftli menteşeli bir protez kullanılabilir; rotasyon yapabilen bir menteşeli protez kullanmak, kemik ile implant arasındaki rotasyonel stresi azaltır ve rotasyon hareketine izin verir. ${ }^{[27]}$ Rahman ve ark. ${ }^{[4]}$, rotasyon yapabilen menteşeli diz protezi ile revize edilen 17 


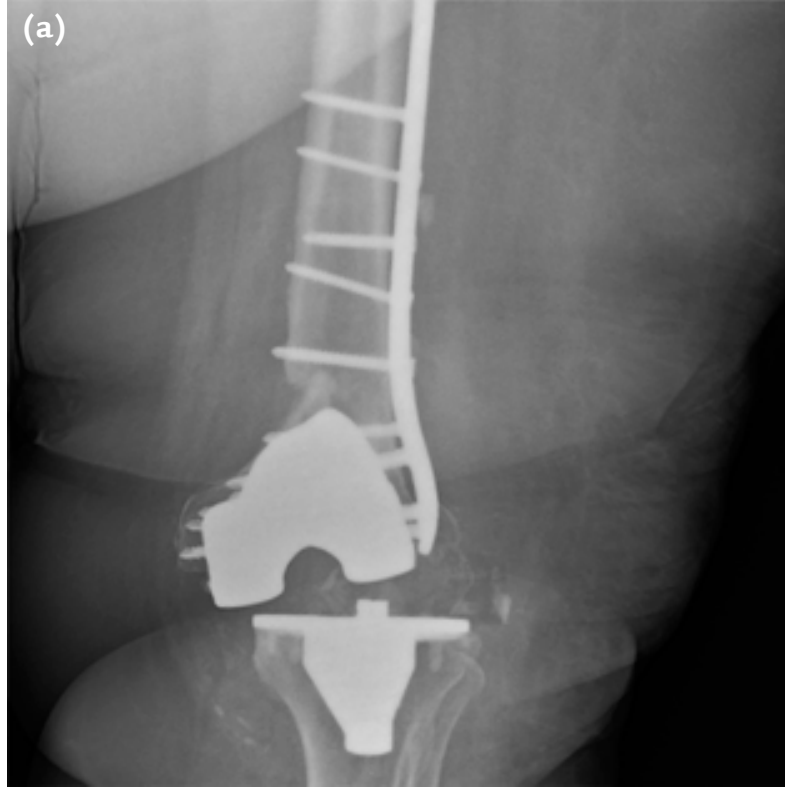

Şekil 3. a-d. Periprostetik femur kırığı ile lateral plaklı osteosentez yapılmış ve redüksiyon kaybı sonrası revizyon TDA'ya giden olgu: Osteosentez sonrası 2. ay AP ve lateral grafileri (a, b). Revizyon sonrası AP ve lateral grafileri (c, d).
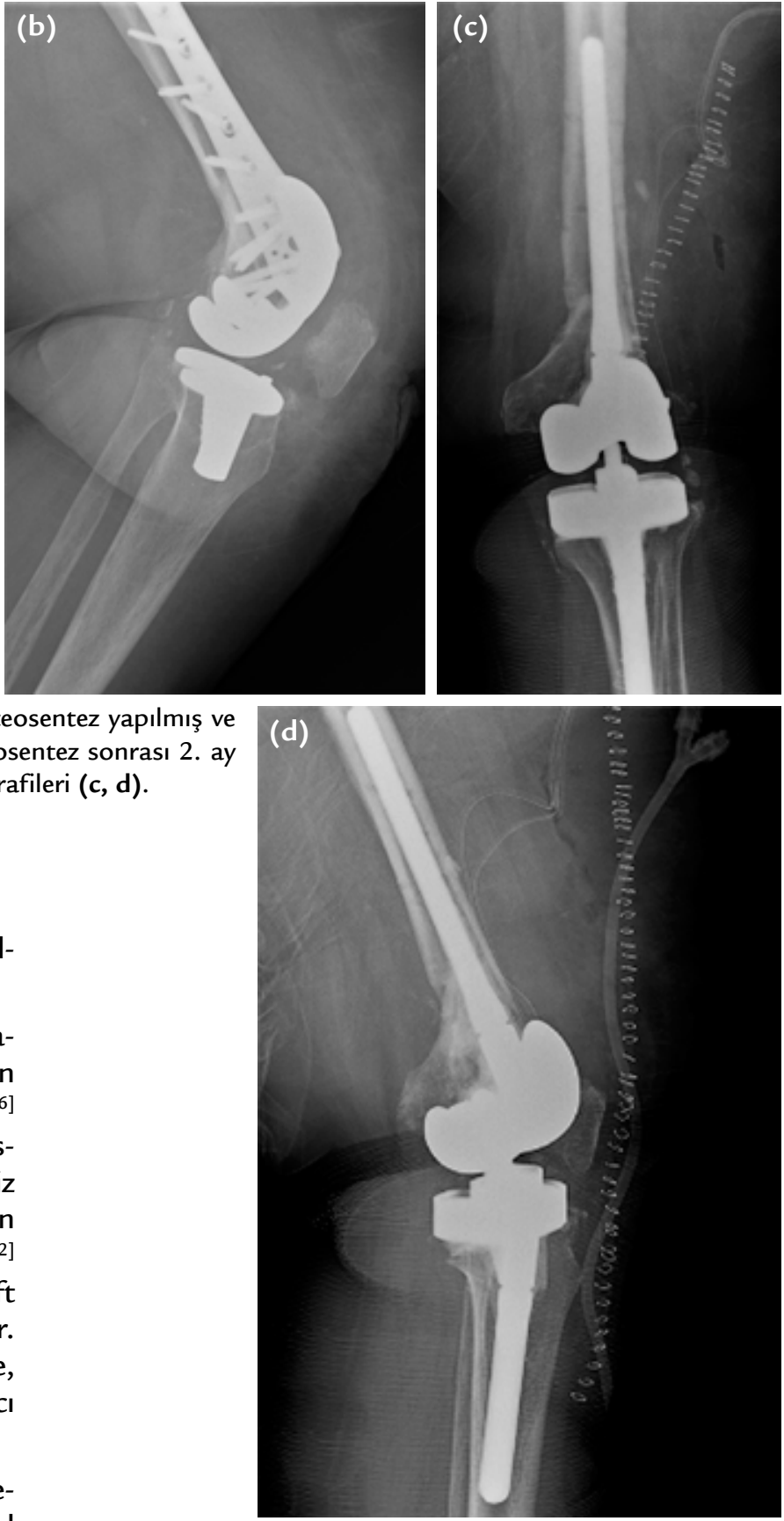

Tibia

Ameliyat sırasındaki tibial periprostetik kırıkların çoğunluğu plato bölgesini içerir ve genellikle nondeplasedir. ${ }^{[15,16]}$ Bu kırıklar, ameliyat sonrası yükten kurtarma ile yönetilebilir. ${ }^{[15,16]}$ Ameliyat sonrası Tip I periprostetik tibia kırıklarında, tibial komponentin varus dizilimde olması muhtemel olduğu için genellikle revizyon önerilmektedir. ${ }^{[49]}$ Mediyal platodaki defektin metal veya kemik desteği ile kapatılması da genellikle gerekir. ${ }^{[49]}$ Tip II kırıklarda, komponent stabilse ve 
minimal deplasman varsa, genellikle cerrahi dışı tedavi tavsiye edilir. ${ }^{[15]}$ Deplase Tip II kırıklarda internal tespit yapılır; protez gevşemesi varsa, kırık hattını geçecek uzunlukta stemli bir komponent kullanan revizyon cerrahisi gereklidir. ${ }^{[49]}$ Stabil bileşenli Tip III kırıklarda, internal tespit yapılarak veya yapılmadan kırık redüksiyonu gerekebilir. ${ }^{[15]}$ Nadir Tip IV kırıklar, açık redüksiyon, internal tespit ve kırık oluşumuna yol açabilecek osteolitik defektin greftlenmesi ile tedavi edilir. ${ }^{[15]}$

\section{Patella}

Patella kırıkları kırık morfolojisi, ekstansör mekanizma devamlılı̆ı ve patella yüzey yenileme implantının stabilitesi göz önüne alınarak tedavi edilir. Bu nedenle, tedavi için kılavuz olarak patella kırıklarına yaklaşımda Goldberg sınıflandırması ${ }^{[50]}$ yararlı bir şekilde kullanılabilir. Buna göre, Tip I kırıklar, stabil bir implant, stabil kırık paternine sahip ve devamlılığı bozulmamış ekstansör aparat ile karakterize, en sık görülen tip olarak bildirilmiştir. Özellikle bu durumlarda, konservatif tedavi ile başarılı bir sonuca varılabilir. ${ }^{[20]}$ Tip II kırıklar ekstansör aparatın devamlılığının bozulduğu ve/veya patellar komponent gevşemesi olan deplase kırıklardır. Bu kırıklarda, olguların \%92'sine varan oranlarda, internal tespitin başarısızlığa neden olduğu bildirilmiştir. ${ }^{[8]} \mathrm{Bu}$ nedenle, komplikasyon oranları olguların \%50'sine ulaşabilse de, ekstansör aparat onarımı ile parsiyel patellektomi daha sık tercih edilir. ${ }^{[20,25]}$ Patellar bağ yırtığının eşlik ettiği veya etmediği, patella alt uç kırı̆̆ı olarak tanımlanan Tip III kırıklarda, implant gevşemesi mevcutsa, kalan kemik stoğu dikkate alınması gereken ana konudur. Patella yüzey düzeltme implantının revizyonu, minimum 10 mm'lik bir kalan kemik kalınlığı varsa başarılı olabilir. ${ }^{[14]}$ Aksi halde, klinik sonuçları tartışılabilir olsa da, kısmi veya total patellektomi tercih edilir. ${ }^{[20,25]}$ Tip IV kırıklar ise, herhangi bir kırık türüne patella dislokasyonu eşlik etmesi olarak tanımlanmıştır. Yüksek komplikasyon oranları ve bütün cerrahi seçeneklerdeki başarısızlık oranları göz önüne alındığında, bazı yazarlar, Goldberg Tip II ve III kırıklarında, özellikle semptomatik olmayanlarda konservatif tedaviyi önermişlerdir. ${ }^{[51]}$

\section{SONUÇ}

Tedavinin en büyük zorluğu, kırığa neden olan bozulmuş kemik kalitesine ilişkindir. Uygun kemik kesimleri yapılması, komponentlerin doğru konumlandırılması, komponentlerin hassas şekilde yerleştirilmesi, komponentlerin ve çimentoların çıkarılması sırasında özenli olunması ve stres arttırıcılardan kaçınılması gerekmektedir. Bu kırıkları yöneten cerrahlar, sorunların farkında olmalı ve başlangıçta planlanan tedavinin gerçekleştirilememesi durumunda ameliyathanede her zaman alternatif tedavi stratejileri hazır olmalıdır. Tedavinin ana hedefleri olan fonksiyonel iyileşme ve ağrısız eklem, TDA sonrası periprostetik kırı̆ı̆ olan hastaların çoğunda sağlanabilir.

\section{KAYNAKLAR}

1. Dennis DA. Periprosthetic fractures following total knee arthroplasty. Instr Course Lect 2001;50:379-89.

2. Ricci WM. Periprosthetic Femur Fractures. J Orthop Trauma 2015;29(3):130-7. Crossref

3. Haller JM, Kubiak EN, Spiguel A, Gardner MJ, Horwitz DS. Intramedullary Nailing of Tibial Shaft Fractures Distal to Total Knee Arthroplasty. J Orthop Trauma 2014;28(12):e296-300. Crossref

4. Herrera DA, Kregor PJ, Cole PA, Levy BA, Jönsson A, Zlowodzki $M$. Treatment of acute distal femur fractures above a total knee arthroplasty: Systematic review of 415 cases (19812006). Acta Orthop 2008;79(1):22-7. Crossref

5. Ritter MA, Faris PM, Keating EM. Anterior femoral notching and ipsilateral supracondylar femur fracture in total knee arthroplasty. J Arthroplasty 1988;3(2):185-7. Crossref

6. Canton G, Ratti C, Fattori R, Hoxhaj B, Murena L. Periprosthetic knee fractures. A review of epidemiology, risk factors, diagnosis, management and outcome. Acta Biomed 2017;88(2S):118-28. Crossref

7. Culp RW, Schmidt RG, Hanks G, Mak A, Esterhai JL, Heppenstall RB. Supracondylar fracture of the femur following prosthetic knee arthroplasty. Clin Orthop Relat Res 1987;(222):212-22. Crossref

8. Chalidis BE, Tsiridis E, Tragas AA, Stavrou Z, Giannoudis P $\mathrm{V}$. Management of periprosthetic patellar fractures. Injury 2007;38(6):714-24. Crossref

9. Lombardi AV, Mallory $\mathrm{TH}$, Waterman RA, Eberle RW. Intercondylar distal femoral fracture: An unreported complication of posterior-stabilized total knee arthroplasty. J Arthroplasty 1995;10(5):643-50. Crossref

10. Lesh ML, Schneider DJ, Deol G, Davis B, Jacobs CR, Pellegrini VD. The consequences of anterior femoral notching in total knee arthroplasty. A biomechanical study. J Bone Joint Surg Am 2000;82-A(8):1096-101. Crossref

11. Ritter MA. The Effect of Femoral Notching During Total Knee Arthroplasty on the Prevalence of Postoperative Femoral Fractures and on Clinical Outcome. J Bone Joint Surg Am 2005;87(11):2411-4. Crossref

12. Gujarathi N, Putti AB, Abboud RJ, MacLean JGB, Espley AJ, Kellett CF. Risk of periprosthetic fracture after anterior femoral notching. Acta Orthop 2009;80(5):553-6. Crossref

13. Hoffmann MF, Jones CB, Sietsema DL, Koenig SJ, Tornetta P. Outcome of periprosthetic distal femoral fractures following knee arthroplasty. Injury 2012;43(7):1084-9. Crossref

14. Parvizi J, Jain N, Schmidt AH. Periprosthetic Knee Fractures. J Orthop Trauma 2008;22(9):663-71. Crossref

15. Felix NA, Stuart MJ, Hanssen AD. Periprosthetic fractures of the tibia associated with total knee arthroplasty. Clin Orthop Relat Res 1997;345:113-24. Crossref

16. Engh GA, Ammeen DJ. Periprosthetic fractures adjacent to total knee implants: treatment and clinical results. Instr Course Lect 1998;47:437-48. 
17. Lotke PA Ecker ML. Influence of positioning of prosthesis in total knee replacement. J Bone Joint Surg Am 1977;59(1):779. Crossref

18. Merkel KD, Johnson EW Jr. Supracondylar fracture of the femur after total knee arthroplasty. J Bone Joint Surg Am 1986;68(1):29-43. Crossref

19. Erak S, Bourne RB, MacDonald SJ, McCalden RW, Rorabeck $\mathrm{CH}$. The cemented inset biconvex patella in revision knee arthroplasty. Knee 2009;16(3):211-5. Crossref

20. Ortiguera CJ, Berry DJ. Patellar fracture after total knee arthroplasty. J Bone Joint Surg Am 2002;84(4):532-40. Crossref

21. Kusuma SK, Puri N, Lotke PA. Lateral Retinacular Release During Primary Total Knee Arthroplasty. J Arthroplasty 2009;24(3):383-90. Crossref

22. Rorabeck $\mathrm{CH}$, Taylor JW. Periprosthetic fractures of the femur complicating total knee arthroplasty. Orthop Clin North Am 1999;30(2):265-77. Crossref

23. Su ET, DeWal H, Di Cesare PE. Periprosthetic Femoral Fractures Above Total Knee Replacements. J Am Acad Orthop Surg 2004;12(1):12-20. Crossref

24. Kim KI, Egol KA, Hozack WJ, Parvizi J. Periprosthetic Fractures after Total Knee Arthroplasties. Clin Orthop Relat Res 2006;446:167-75. Crossref

25. Yoo JD, Kim NK. Periprosthetic Fractures Following Total Knee Arthroplasty. Knee Surg Relat Res 2015;27(1):1-9. Crossref

26. Moran MC, Brick GW, Sledge CB, Dysart SH, Chien EP. Supracondylar Femoral Fracture Following Total Knee Arthroplasty. Clin Orthop Relat Res 1996;324:196-209. Crossref

27. McGraw $P$, Kumar A. Periprosthetic fractures of the femur after total knee arthroplasty. J Orthop Trauma 2010;11(3):13541. Crossref

28. Davison BL. Varus collapse of comminuted distal femur fractures after open reduction and internal fixation with a lateral condylar buttress plate. Am J Orthop (Belle Mead NJ) 2003;32(1):27-30.

29. Kolb K, Koller H, Lorenz I, Holz U, Marx F, P Grützner, Kolb $W$. Operative treatment of distal femoral fractures above total knee arthroplasty with the indirect reduction technique. Injury 2009;40(4):433-9. Crossref

30. Mamczak CN, Gardner MJ, Bolhofner B, Borrelli J, Streubel PN, Ricci WM. Interprosthetic Femoral Fractures. J Orthop Trauma 2010;24(12):740-4. Crossref

31. Henderson CE, Kuhl LL, Fitzpatrick DC, Marsh JL. Locking Plates for Distal Femur Fractures: Is There a Problem With Fracture Healing? J Orthop Trauma 2011;25:S8-14. Crossref

32. Cain PR, Rubash HE, Wissinger HA, McClain EJ. Periprosthetic femoral fractures following total knee arthroplasty. Clin Orthop Relat Res 1986;(208):205-14. Crossref

33. Maniar RN, Umlas ME, Rodriguez JA, Ranawat CS. Supracondylar femoral fracture above a PFC posterior cruciate-substituting total knee arthroplasty treated with supracondylar nailing. A unique technical problem. J Arthroplasty 1996;11(5):637-9. Crossref

34. Thompson SM, Lindisfarne EAO, Bradley N, Solan M. Periprosthetic Supracondylar Femoral Fractures Above a Total Knee Replacement: Compatibility Guide for Fixation With a Retrograde Intramedullary Nail. J Arthroplasty 2014;29(8):1639-41. Crossref

35. Gliatis J, Megas P, Panagiotopoulos E, Lambiris E. Midterm results of treatment with a retrograde nail for supracondylar periprosthetic fractures of the femur following total knee arthroplasty. J Orthop Trauma 2005;19(3):164-70. Crossref
36. Ebraheim NA, Kelley LH, Liu X, Thomas IS, Steiner RB, Liu J. Periprosthetic Distal Femur Fracture after Total Knee Arthroplasty: A Systematic Review. Orthop Surg 2015;7(4):297-305. Crossref

37. Large TM, Kellam JF, Bosse MJ, Sims SH, Althausen $\mathrm{P}$, Masonis JL. Locked Plating of Supracondylar Periprosthetic Femur Fractures. J Arthroplasty 2008;23(6):115-20. Crossref

38. Pelfort $X$, Torres-Claramunt R, Hinarejos $P$, Leal J, GilGonzález S, Puig L. Extension Malunion of the Femoral Component After Retrograde Nailing. J Orthop Trauma 2013;27(3):158-61. Crossref

39. Ristevski B, Nauth A, Williams DS, Hall JA, Whelan DB, Bhandari M, Schemitsch EH. Systematic Review of the Treatment of Periprosthetic Distal Femur Fractures. J Orthop Trauma 2014;28(5):307-12. Crossref

40. Çiçek H, Tuhanioğlu Ü, Oğur HU, Seyfettinoğlu F, Bozkurt M. An alternative treatment for osteoporotic Su Type III periprosthetic supracondylar femur fractures: Double locking plate fixation. Acta Orthop Traumatol Turc 2018;52(2):926. Crossref

41. Mortazavi SMJ, Kurd MF, Bender B, Post Z, Parvizi J, Purtill JJ. Distal Femoral Arthroplasty for the Treatment of Periprosthetic Fractures After Total Knee Arthroplasty. J Arthroplasty 2010;25(5):775-80. Crossref

42. Kraay MJ, Goldberg VM, Figgie MP, Figgie HE. Distal femoral replacement with allograft/prosthetic reconstruction for treatment of supracondylar fractures in patients with total knee arthroplasty. J Arthroplasty 1992;7(1):7-16. Crossref

43. Madsen F, Kjaersgaard-Andersen P, Juhl M, Sneppen O. A custom-made prosthesis for the treatment of supracondylar femoral fractures after total knee arthroplasty: report of four cases. J Orthop Trauma 1989;3(4):332-7. Crossref

44. Wong $\mathrm{P}$, Gross AE. The use of structural allografts for treating periprosthetic fractures about the hip and knee. Orthop Clin North Am 1999;30(2):259-64. Crossref

45. Rahman WA, Vial TA, Backstein DJ. Distal Femoral Arthroplasty for Management of Periprosthetic Supracondylar Fractures of the Femur. J Arthroplasty 2016;31(3):676-9. Crossref

46. Keenan J, Chakrabarty G, Newman JH. Treatment of supracondylar femoral fracture above total knee replacement by custom made hinged prosthesis. Knee 2000;7(3):165-70. Crossref

47. Gondalia $\mathrm{V}$, Choi DH, Lee SC, Nam CH, Hwang BH, Ahn HS, Ong AC, Park HY, Jung KA. Periprosthetic supracondylar femoral fractures following total knee arthroplasty: clinical comparison and related complications of the femur plate system and retrograde-inserted supracondylar nail. J Orthop Traumatol 2014;15(3):201-7. Crossref

48. Figgie MP, Goldberg VM, Figgie HE, Sobel M. The results of treatment of supracondylar fracture above total knee arthroplasty. J Arthroplasty 1990;5(3):267-76. Crossref

49. Rand JA, Coventry MB. Stress fractures after total knee arthroplasty. J Bone Joint Surg Am 1980;62(2):226-33. Crossref

50. Goldberg VM, Figgie HE, Inglis $A E$, Figgie MP, Sobel $M$, Kelly M, Way M. Patellar fracture type and prognosis in condylar total knee arthroplasty. Clin Orthop Relat Res 1988;(236):115-22. Crossref

51. Keating EM, Haas G, Meding JB. Patella Fracture After Post Total Knee Replacements. Clin Orthop Relat Res 2003;416:93-7. Crossref 